\title{
Interuniversity cooperation and university-enterprise partnership in the framework of the programmes of the European Community (EC)
}

\author{
A. Van der Beken \\ Laboratory of Hydrology, Faculty of Applied Sciences, \\ Vrije Universiteit Brussel (VUB) \\ Coordinator for ERASMUS and COMETT projects
}

\section{Introduction}

The Task Force Human Resources, Education Training and Youth of the Commission of the European Communities had launched in 1987 two flagship programmes known under the acronyms ERASMUS and COMETT.

Both programmes are promoting networks:

- cooperating universities in the case of ERASMUS and - universities and enterprises in the case of COMETT.

Essentiel is the fact that these networks must be transnational and are aimed at developping education and training. They are NOT dealing with research. The general goals of these programmes are a closer contact among Europeans, cornerstone of our common future, and a pooling of intellectual skills to foster our international competitiviness.

The programmes offer an opportunity and a challenge to cooperating for education and training across country borders, for the benefit of both students and teachers as well as for the advancement of scientific activities.

Another very important characteristic of both programmes is the straightforward procedure : any promoter of a network, as defined above, can apply. It is NOT the university as a body which should apply but the laboratory or department and its coordinator. Of course « letters of endorsement " signed by the highest authority in both universities and enterprises are requested in order to give the necessary official status to the proposed network.

2. The ERASMUS ICP-interuniversity cooperation programme for hydrology and water management

It started in 1988 with a grant for preparatory visits : the possibility for establishing an ICP was studied and an "Outline for cooperation in the field of Hydrology and Water Management » was sent around.
Note that applications for visit grants are also accepted for exploratory contacts with the aim of extending an existing ICP.

ICP-89 counted 10 partners from 5 EC-countries (B, E, F, I, UK) but only 4 partners were active : there was a flow of 4 students, each of them studying 4 months abroad, either taking courses or preparing a thesis, and very important, taking language courses.

At the same time there was a flow of three lecturers : staff mobility is very useful as well for the improvement of the teaching spectrum and quality of each department as for monitoring the host-students.

ICP-89 counts 24 partners from 8 EC-countries (B, D, E, F, I, NL, P, UK). A student mobility flow of 47 for a total of 294 months was projected but due to grantrestrictions this flow will probably be smaller. The staff mobility is now 7 , including teaching topics such as fluid mechanics, groundwater hydrology, advanced surface water hydrology, statistical applications, water resources management, reservoir management.

Four intensive programmes, of 7 to 10 days each, were proposed and three were accepted. They are organized at the PhD-level and cover Geostatistics in hydrology, Karstic hydrology, and Isotope hydrology.

One partner from Valencia (E) developed a MSc programme in Hydrology and Water Resources Management with an option to Urban Water Management, as part of the ICP.

The new application for ICP-91 shows again an increase in student and teaching staff mobility as well as in proposals for intensive programmes.

Future developments should include the production of a "course-directory ", the implementation of a common ERASMUS credit-system (so called ECTS-European Course Credit Transfer System), the generalized use of the STUDY-PLAN and Academic Record procedures.

The question arises if there is a need for a European (postgraduate) degree in hydrology and water management. If this question is yes, its development and organisation is a typical task for the ICP. 
Already now we can quote from the "Report on the experience acquired in the application of the ERASMUS programme 1987-89 (Ref. SEC/89/2051 Brussels, 13.12.1989) and add :

... the emergence of a new generation of graduates (in the field of hydraulics, hydrology and water management) who possess an experience of living and working in several Community countries and have qualifications with European "added value" which is the gateway to a (water-) labour market of Community dimensions.

\section{COMETT and TECHWARE}

COMETT I (1987-1990) supported in a modest way two projects in "Water Resources Technology": one in Strand $\mathrm{Ba}$ " Placement of Students in Enterprises " during the periods $1988-89$ and $1989-90$ and one in Strand D " Expert systems for computer aided design and renovation of sewer networks " from 1987 till 1990.

This network counted 10 universities and 18 enterprises from 9 countries This small network had the advantage of easy mutual acquaintanceship and relatively high active participation, but at the same time it lacked the resources and funds to develop and to give a full European dimension to training for water resources technology.

The second phase - COMETT II - of the Programme for intra-Community cooperation between universities and industry regarding initial and continuing training in the field of, in particular, advanced technology, was adopted by the Council, on 16 December 1988, for a period of five years beginning on 1 January 1990.

The broadened objectives of COMETT II are the following :

(i) to improve the contribution of, in particular, advanced technology training at the various levels concerned and thus the contribution of training to the economic and social development of the Community.

(ii) to foster the joint development of training programmes and the exchange of experience, and also the optimum use of training resources at Community level, notably through the creation of transnational sectoral and regional networks of, in particular, advanced technology training projects.

(iii) to respond to the specific skill requirements of small and medium-sized businesses.

(iv) to promote equal opportunities for men and women in initial and continuing training in, in particular, advanced technology.

(v) to give a European dimension to cooperation between universities and industry in initial and continuing training relating to technologies and their applications and transfer.

Thus, COMETT II provided the nex opportunity to found a sectoral network for water resources technology.

Two preliminary meetings in early 1990 showed sufficient interest from ca. 30 partners. However, at the deadline for the proposals, the network had been growing up to 89 partners. The network or UETP-University Enterprise Training Partnership, as defined by COMETT, was called TECHWARE-TECHnology for Water REsources.

TECHWARE was founded on 6 July 1990 and given the legal status of an international non-profit-making association under Belgian law, governed by its General Assembly of all members and managed by its Board of Directors and its Executive Committee. A Secretary-General has been appointed.

The objectives of TECHWARE are :

- multidisciplinary training-partnership promoting advanced technologies and methodologies for integrated water management ;

- promoting cooperation, innovation and analysis of needs in the field of education, training and quick transfer of research results;

- addressing especially the SMEs-small and mediumsized enterprises ;

- promoting and realizing the exchange of students, young graduates and personnel;

- developing and disseminating educational and training materials ;

- promoting and organizing activities focused on continuous education;

- promoting participation of the members in other European and international programmes in all water related fields.

The latter objective was realized for the first time soon after the foundation: TECHWARE coordinates TEMPUS-proposals of its members (see hereafter) and quoted also for a tender under the MONITOR/SAST Programme of EC, i.e. SAST (Strategic Analysis in Science and Technology) Project No. 6: "Research and Technological Development for the Supply and Use of Freshwater Resources." The TECHWARE proposals gathered 28 partners from 10 EC-countries : an excellent example of a cooperative activity among universities and enterprises with a truly European dimension.

It should be stressed that TECHWARE has an open membership for all those with water-related interests : members cooperate on a voluntary basis, in mutural trust and with clear offerings.

TECHWARE highly appreciates collaboration with other associations to realize its objectives. As a matter of fact, the scientific and professional associations, both at the national and international level, are privileged partners. They can help and cooperate in many ways with respect to the TECHWARE-activities all over Europe.

For the period 1990-1991 the following activities are underway: (*accepted for funding by COMETT II).

STRAND B : TRANSNATIONAL EXCHANGES.

*BA : placement of students.

${ }^{*} \mathrm{Bb}$ : placement of young graduates.

$\mathrm{Bc}$ : exchange of personnel. 


\section{STRAND C : JOINT TRAINING ACTIONS.} Ca : CARSH TRAINING COURSES.

1. Field measurements and instrumentation for sewer systems.

2. Advanced courses of geohydrology.

*3. Aquatic ecotoxicology.

*4. Computer aided irrigation systems.

5. Radars in urban drainage.

$\mathrm{Cb}$ : DEVISING, DEVELOPING AND TESTING JOINT TRAINING PROJECTS.

*1. Advanced computer techniques for the design and renovation of sewer systems.

*2. Integrated urban-storm and wastewater management. Training by distance learning based on the electronic classroom.

3. Advanced training courses in river engineering.

4. Training for management and renovation of large irrigation canals.

STRAND D : PREPARATORY ACTIVITIES PARTICULARY FOR THE LESS DEVELOPED REGIONS.

New proposals for transnational exchanges, crash training courses and preparatory visits are due 31 January 1991.

\section{TEMPUS}

The goals of the Trans-European Mobility Scheme for University Studies are :

- contribution to the medium-and longer-term development of the higher education and training systems inside the Central/Eastern European (CEE-)countries, starting with Poland and Hungary;

- interaction of these countries with the European Community and other Western countries through joint activities and growing staff and student mobility.

Among the priority areas are :

- applied sciences and technologies,

- environmental production.

The grants provided within the scheme fall into three broad categories.

\section{a. Joint European projects}

— support for joint training projects linking universities and/or enterprises in Central/Eastern European countries with equivalent partners in the European Community.

\section{b. Mobility grants for teachers/trainers, students/trainees and administrators}

— grants for periodes of study;

- grants for teaching/training assignment ;

- grants for practical placements in industry, administration, research centres or universities ;
- visit grants for teachers/trainers, university administrators and other training experts.

\section{c. Grants for complementary actions}

- youth exchanges ;

- participation in European assocations;

- support for publications and informations;

- surveys, analysis and monitoring.

Since TECHWARE counts already membership in several CEE-countries, it was clear from the start that important Joint European Projects (JEPs) could be assembled in which most partners are already members of TECHWARE.

\section{PANTA RHEI}

PANTA RHEI : "all things are in constant flux " is an axioma of Heraclitus quoted by Plato. It is the name of a quarterly information bulletin, launched in September 1989 and edited by the author and several colleagues on behalf of the partners in the field of hydrology, water management and water resources technology. It is published with the financial support of the European Community in the framework of the ERASMUS and COMETT programmes and distributed free of charge. The present distribution it 2500 copies. Issues are published in September, December, March and June.

The objectives of PANTA RHEI are:

- an efficient and continuous way of communication among all ERASMUS, COMETT and TEMPUS partners, both active and prospective, and among students and training participants with interest in water related fields ;

- service to the UETP-University Enterprise Training Partnership: TECHWARE-TECHnology of WAter REsources ;

- dissemination of activities or proposals of partners, in particular ;

* transnational exchanges of students, young graduates and staff ;

* joint development of full curricula or specific training tools ;

* crash or intensive courses ;

* analysis of training needs ;

— information about other wate related training activities ;

- promotion of a European dimension in the field of water-related education and training.

PANTA RHEI is not a scientific journal nor a technical magazine and therefore should be considered as a complementary rather than a competing bulletin in the world of water-related publications and magazines. We do hope that it fulfils its objectives and that it can offer a forum to all those interested in education and training. 


\section{Conclusions}

The pace at which Europe - and not only the EC develops strikes necessarily also the educational activities and training at all levels in hydraulics and related disciplines. The EC-programmes ERASMUS, COMETT and TEMPUS are especially geared to developping and establishing networks for cooperation among universities (ERASMUS) and universities/enterprises (COMETT, TEMPUS).

These networks should receive all our attention and support. The above described networks are only examples, but show the potential and the challenge for effective cooperation if one agrees about the European «added value». As a teacher and from his own experience, the author strongly believes in the unmeasurable benefit of transnational exchanges, for students as well as for staff and personnel. Also, the rapid dissemination of research results by intensive courses, crash courses and training projects is a goal we all share.

The perspective of developing European study programmes is a challenging issue which should be investigated and tried out step by step.

The scientific and professional associations could play an important role in the COMETT and TEMPUS framework. 